\title{
O TELETRABALHO NA JUSTIÇA DO TRABALHO DA 4ㄹ REGIÃO E O PRINCÍPIO DA SUSTENTABILIDADE
}

\begin{abstract}
Denise Pires Fincato
Possui graduação em Direito pela Universidade do Vale do Rio dos Sinos (1994), Mestrado em Direito pela Universidade do Vale do Rio dos Sinos (1999), Doutorado em Direito Universidad de Burgos (2001). Atualmente é professora da Pontificia Universidade Católica do Rio Grande do Sul, com ênfase na pós-graduação, onde ministra as disciplinas de Metodologia da Pesquisa Jurídica e Novas Tecnologias e Relações de Trabalho. Na graduação e pós-graduação, leciona ainda as disciplinas de Direito do Trabalho, Prática e Processo do Trabalho. É pesquisadora do CNPq, FAPERGS, FAPEMA, onde desenvolveu/desenvolve pesquisas envolvendo os temas: ensino jurídico, trabalho infantil, teletrabalho, processo eletrônico, direito laboral e inovações tecnológicas. Possui experiência na administração acadêmica, tendo sido coordenadora do Departamento de Prática Jurídica da PUCRS (20052008) e coordenadora de curso (2005-2008). Integrou a lista tríplice (2008) e a lista sêxtupla (2012) para preenchimento da vaga de Desembargador Federal do Trabalho resenada aos advogados no Tribunal Regional do Trabalho da 4⿳亠丷厂 Região (quinto constitucional). Integrante do Tribunal de Ética e Disciplina da OAB/RS. Conselheira da AGETRA - Associação Gaúcha dos Advogados Trabalhistas (2010-2012). Diretora Cultural da AGETRA - Associação Gaúcha dos Advogados Trabalhistas (2013-2015). Conselheira Estadual na OAB/RS (2016-2019). Advogada e Consultora na área trabalhista, sócia do escritório Souto, Correa, Cesa, Lummertz e Amaral Advogados. Coordenadora do Grupo de Pesquisas Novas Tecnologias, Processo e Relações de Trabalho - CNPq/PUCRS. Porto Alegre, Rio Grande do Sul.
\end{abstract}

\section{Daniel Pires Christofoli}

Advogado formado pela Pontifícia Universidade Católica - PUCRS. Especialista em Direito Público pelo Instituto de Desenvolvimento Cultural - IDC e pela Escola Superior da Magistratura Federal - ESMAFE. Mestre em Direito pela Uniritter/RS. Consultor Jurídico do Instituto Gamma de Assessoria a Órgãos Públicos - IGAM. Integrante do Grupo de Pesquisa Novas Tecnologias, Processo e Relações de Trabalho, coordenado pela Profa. Dra. Denise Pires Fincato, vinculado ao Programa de Pós-Graduação em Direito da PUCRS - PPGD/ PUCRS. Porto Alegre, Rio Grande do Sul.

Resumo: Este estudo tem por objetivo realizar a análise da Resolução no 151, de 2015, do Conselho Superior da Justiça do Trabalho (CSJT), bem como, ao fundo, da Portaria ํㅡ 5.791, de 07 de agosto de 2013, expedida pelo Tribunal Regional do Trabalho da 4를 Região, e que promove o teletrabalho perante a Justiça do Trabalho da 4a Região. A leitura, para esta empreitada, será realizada tendo por base jurídica o princípio da sustentabilidade, que reflete dever de nova postura da Administração Pública diante do Direito Administrativo.

Palavras-chave: Teletrabalho. Sustentabilidade. Tribunal do Trabalho da 4a Região. Resolução no 109, de 2012. Conselho Superior de Justiça do Trabalho.

Sumário: Introdução - 1 Teletrabalho: conceito e contextualização perante o (novo) Direito Administrativo - 2 A regulamentação do teletrabalho na Justiça do Trabalho da 4ํ Região: sustentabilidade - Conclusão - Referências 


\section{Introdução}

Este estudo possui por tema a análise da Resolução no 151, de 2015, do Conselho Superior da Justiça do Trabalho (CSJT), que promoveu a inserção do teletrabalho no âmbito da Justiça do Trabalho, tendo como tela de fundo a Portaria no 5.791, de 07 de agosto de 2013, que aplicou a regulamentação na Justiça do Trabalho da 4⿳亠口冋 Região.

Ademais, o objetivo pretendido é pesquisar a matéria, e seus elementos, tendo por parâmetro o instituto do teletrabalho perante o princípio da sustentabilidade, previsto em Freitas (2012), enquanto paradigma para o Direito Administrativo.

Para tanto, o texto é concebido em duas partes. A primeira realiza o conceito de teletrabalho e sua contextualização perante o (novo) Direito Administrativo. A segunda, por sua vez, perfaz a análise do instrumento de regulamentação do

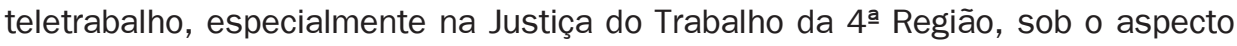
da sustentabilidade.

Neste viés, a segunda parte resta dividida em quatro itens, com o fito de promover uma análise didática da Resolução № 151, de 2015, do CSJT. O primeiro item versa sobre "a estrutura primária" e trabalha os considerandos da norma referida. Por sua vez, o segundo item trata "das disposições gerais aos destinatários", examinando-se do art. 1ํao art. 4ํ da Resolução. Adiante, o terceiro item possui o título "das vedações até as condições para a realização do teletrabalho", onde firma-se análise do art. 5ำ ao art. 16. Por fim, o quarto item emprega o título "das disposições finais" e trabalha do art. 16 até o art. 21 da citada norma regulamentadora.

A pretensão desta pesquisa, presente no seu conteúdo, é indicar a necessidade de debate perante o termo final da experiência do teletrabalho na Justiça do Trabalho da 4a Região, conforme os termos da Portaria no 5.791, de 07 de agosto de 2013, com sua prorrogação pela Portaria no 4.690, de 14 de agosto de 2014, especialmente no contexto do chamado "novo" Direito Administrativo e, em especial, à luz do princípio da sustentabilidade.

\section{Teletrabalho: conceito e contextualização perante 0 (novo) Direito Administrativo}

A introdução do teletrabalho na área pública é tema que se coaduna ao próprio movimento pela evolução de um novo Direito Administrativo. Assim, para o andamento desta parte torna-se importante estabelecer um conceito de teletrabaIho e, posteriormente, colocá-lo no contexto da seara pública, a partir das novas perspectivas e quebras de paradigmas administrativistas. 
Acerca de um conceito de teletrabalho, Teixeira (1996, p. 1310), na metade da década de 90, já referia:

No novo modelo de relação de emprego, a prestação pessoal continua exigida, mas de forma menos rígida. Admite-se a substituição eventual do empregado, notadamente na nova modalidade de emprego a domicílio, como o já citado teletrabalho no home Office, quando o empregado presta serviços na sua própria casa, interligado com a empresa por via de computador ou simples telefone.

Em artigo anteriormente escrito sobre o teletrabalho na Administração Pública brasileira (FINCATO, 2014, p. 19), já se relacionou o impacto das novas tecnologias, bem como dos fatores de globalização da economia ao surgimento de novas profissões e, por que não, de um novo mercado, traduzindo-se isto em marcos pós-modernos que possibilitaram o surgimento de relações de trabalho em espaços internacionais.

Assim, tal qual anteriormente já realizado, é importante direcionar-se a perspectiva do teletrabalho a partir de marcos da modernidade que permitam a expansão das relações de trabalho, partindo-se da perfeita compreensão do instituto:

O teletrabalho significa, de acordo com o que já se teve oportunidade de estudar anteriormente e restrito a uma interpretação literal, "trabalho a distância". Mas não só isto. 0 trabalho a distância deve ter a mediação das tecnologias de informação e comunicação. Daí dizerse que trabalho em domicílio não necessariamente será teletrabalho (FINCATO, 2014, p. 19).

Um bom conceito de teletrabalho é sintetizado por Rocha e Muniz (2013, p. 102):

O teletrabalho pode ser considerado como a prestação de serviços a qualquer título, desde que seja a distância, ou externado, com a utilização dos instrumentos de informática ou telemática, em favor de outrem.

Entende-se que os mesmos marcos outrora relacionados (FINCATO, 2014) podem ser observados a favor do movimento pela quebra de paradigmas do próprio Direito Administrativo, esposados por Freitas (2012), em sua pesquisa acerca do princípio da sustentabilidade - a ser referenciado a seguir - e, ainda, por Binenbojm (2008). 
Binenbojm (2008, p. 24-25) defende a ideia da constitucionalização do Direito Administrativo enquanto alternativa ao que denominou de déficit teórico em torno de paradigmas clássicos desta esfera de direitos. A mudança de paradigma proposta por Binenbojm (2008, p. 29) se complementará com o princípio da sustentabilidade em Freitas (2012). Por hora, torna-se importante indicar o argumento em Binenbojm (2008) enquanto marco para a modernização do próprio Direito Administrativo.

Tem-se, em suma, o argumento a favor da constitucionalização do Direito Administrativo e seus dogmas, dentre eles o interesse público. Segundo Binenbojm (2008, p. 33):

Desde modo, a emergência de um modelo de ponderação, como critério de racionalidade do direito (e do próprio Estado democrático de direito), servirá de instrumento para demonstrar a inconsistência da ideia de um princípio jurídico (ou um postulado normativo aplicativo) que preconize a supremacia abstrata e a priori do coletivo sobre o individual ou do público sobre o privado.

0 argumento serve de pista limpa para o verdadeiro ideal de eficiência, preconizado pela chamada "Reforma Administrativa". Perante a Constituição brasileira, a Emenda Constitucional no 19, de 1998, é instrumento de importância para o ideal de modernização da Administração Pública, eis que insere, no rol de princípios do art. 37, caput, o princípio da eficiência. Tal ocorrência, para Gabardo (2002, p. 17), ganha a seguinte interpretação:

[...] em uma interpretação mais-que-modernizadora, emancipatória, o princípio da eficiência administrativa pode e deve escapar de suas funções de mera legitimação simbólica das novas políticas reformadoras.

O autor assevera que o vetor de eficiência está mais para as pessoas (agentes públicos) e os órgãos públicos (instalados nas pessoas jurídicas que compõem a Administração), assim como o conceito de eficácia está para os atos administrativos, expedidos por aqueles, atrelado à ideia de publicidade e transparência.

De fato, a modernização do Direito Administrativo, a partir da leitura de Gabardo (2002) e Binenbojm (2008) para o princípio da eficiência, demanda a necessidade de que a Administração coadune-se com o impacto das novas tecnologias e demais fatores ressaltados em obras pretéritas (FINCATO, 2014).

Na mesma esteira, porém na seara das relações privadas trabalhistas, a Lei Federal n 12.551, de 15 de dezembro de 2011, alterou o art. 6으 da Consolidação 
das Leis do Trabalho (CLT), aprovada pelo Decreto-Lei no 5.452, de 1ํ de maio de 1943, para equiparar os efeitos jurídicos da subordinação exercida por meios telemáticos e informatizados à exercida por meios pessoais e diretos.

O dispositivo, em questão, passou a ter a seguinte redação:

Art. 6ㅇ Não se distingue entre o trabalho realizado no estabelecimento do empregador, o executado no domicílio do empregado e o realizado a distância, desde que estejam caracterizados os pressupostos da relação de emprego. (Redação dada pela Lei no 12.551, de 2011) Parágrafo único. Os meios telemáticos e informatizados de comando, controle e supervisão se equiparam, para fins de subordinação jurídica, aos meios pessoais e diretos de comando, controle e supervisão do trabalho alheio. (Incluído pela Lei no 12.551, de 2011)

Admitindo as alterações da informática para o mundo, e comentando os efeitos da Lei Federal no 12.551, de 2011, perante a redação do art. 6으 da CLT, Rocha e Muniz (2013, p. 103) afirmam:

O uso dos meios telemáticos e informatizados no mercado produtivo, ao mesmo tempo em que extirpa algumas profissões, cria outras, como o teletrabalho que surgiu da utilização dessas novas tecnologias.

Efetivamente, Rocha e Muniz (2013) estão corretos ao afirmar as inúmeras atividades reconhecidas ou até mesmo criadas com a inserção do teletrabalho na CLT. Observando, então, a perspectiva dos fins preconizados ao teletrabalho e o Direito Administrativo moderno, tem-se a possibilidade de sua inserção na esfera pública.

A iniciativa, em que pese coadunar-se à ideia de projetar um novo modelo de desempenho de tarefas (no caso atribuições, ou competências) pelos agentes públicos da administração, esbarra na lacuna da regulamentação sobre o teletrabaIho na esfera do Direito Público. Fincato (2014, p. 20-21), sobre a regulamentação do teletrabalho na iniciativa privada, já referiu que:

No que concerne ao teletrabalho no Brasil, para as relações de trabalho na esfera privada, ademais da alteração recente do art. 6으 da CLT, remanesce em andamento o projeto de lei oㅡ 4505/2008 que, igualmente, refere-se apenas ao teletrabalho em âmbito de relações privadas.

No âmbito do serviço público, relaciona a então Resolução no 109/2012, hoje sucedida pela Resolução № 151/2015, ambas expedidas pelo Conselho 
Superior da Justiça do Trabalho - CSJT, que regulamentou o teletrabalho no âmbito da Justiça do Trabalho (FINCATO, 2014, p. 21). Posiciona-se pela inconstitucionalidade e ilegalidade do instrumento regulamentar, sustentando violação, em seu conteúdo, a matérias pertencentes ao conteúdo jurídico subjetivo dos servidores públicos civis (FINCATO, 2014, p. 21), firme no que tange aos direitos fundamentais sociais.

Em argumento que se coaduna ao instigado por Fincato (2014), e nesta perspectiva Freitas (2009, p. 30-1) refere que o direito fundamental à boa administração deve garantir o controle sistemático das relações administrativas, no que aduz:

\begin{abstract}
Nesse horizonte, já é passada a hora de os princípios e os direitos fundamentais assumirem maiúsculo papel no controle substancial das relações administrativas. [...] 0 que importa, aqui, porém, é sublinhar que não subsistem razões para a crença em paradigmas simplificadores e irrealistas, de acordo com os quais incumbiria ao administrador/controlador apenas observar regras formais, de maneira irreflexiva $[\ldots]$.
\end{abstract}

Assim, é importante passar à segunda parte deste trabalho, em que se fará a análise acerca dos instrumentos de regulamentação do teletrabalho na esfera administrativa, o que se fará a partir da análise casuística da Resolução $n$ o 151/2015, do Conselho Superior da Justiça do Trabalho - CSJT (ex-Resolução no 109/2012) e, no Tribunal Regional do Trabalho do Rio Grande do Sul (TRT 4a Região), pela Portaria ํo 5.791, de 2013.

\title{
2 A regulamentação do teletrabalho na Justiça do Trabalho da 4ª Região: sustentabilidade
}

\subsection{A estrutura primária}

Ratifica-se que este trabalho, no particular, tem por intenção a análise da Resolução no 151/2015, do Conselho Superior da Justiça do Trabalho - CSJT, tendo como instrumento concretizador regional a Portaria no 5.791, de 07 de agosto de 2013, ato regulamentador do teletrabalho no Tribunal Regional do Trabalho da 4aㅡ Região a partir da perspectiva do princípio da sustentabilidade preconizado por Freitas (2012).

Ao buscar o conceito de sustentabilidade, as palavras de Freitas (2012, p. 41) são elucidativas: 
[...] trata-se do princípio constitucional, com eficácia direta e imediata, a responsabilidade do Estado e da sociedade pela concretização solidária do desenvolvimento material e imaterial, socialmente inclusivo, durável e equânime, ambientalmente limpo, inovador, ético e eficiente, no intuito de assegurar, preferencialmente de modo preventivo e precavido, no presente e no futuro, o direito ao bem-estar.

O princípio força uma robusta guinada de rota (FREITAS, 2012, p. 195) em velhos paradigmas do Direito Administrativo, faceta marcante que pode ser percebida na regulamentação pretendida para o teletrabalho no âmbito da Justiça do Trabalho.

Neste viés, Freitas (2012, p. 41) orienta que estão reunidos no conceito de sustentabilidade certos elementos - que deverão estar observados no instrumento normativo a ser analisado -, dentre outros, o da natureza de princípio constitucionalmente aplicável (o que demanda sua consonância ao rol de direitos fundamentais e sociais, frisa-se); o encontro de resultados justos (eficácia das medidas propostas); a eficiência (enquanto uso de meios idôneos e, também, igualitários), a probidade (enquanto dever de evitar danos certos) e a precaução (dever de evitar danos prováveis, restando, nesta, a possível violação a direitos).

Por entender de sua competência, então, o Conselho expediu a Resolução no 151, de 29 de maio de 2015, que traz em sua ementa: “Incorpora a modalidade de teletrabalho às práticas dos órgãos do Judiciário do Trabalho de primeiro e segundo graus, de forma facultativa, observada a legislação vigente". Em seu artigo $1^{\circ}$, a Resolução estabiliza o quadro antes ainda experimental, estatuindo que "A realização do teletrabalho fica incorporada às práticas institucionais dos órgãos do Judiciário do Trabalho de primeiro e segundo graus, de forma facultativa, observada a legislação vigente". Guise-se que a resolução antecedente (109/2012) encerrava-se com a observação de que o teletrabalho era admitido em caráter experimental e, assim também, o texto resolutivo.

$\mathrm{O}$ ato administrativo regulamentar, em âmbito regional (limite da competência do Estado do Rio Grande do Sul), segue sendo (ao menos até o fechamento deste artigo) a Portaria no 5.791, de 07 de agosto de 2013, exarada pela Presidência do Tribunal Regional do Trabalho da 4a Região (TRT 4a Região) que, por seu conteúdo e disposições, entende-se confortada na Resolução de 2015, do CSJT.

Ambos os instrumentos regulamentadores são de grande importância para o advento do teletrabalho no Tribunal Regional do Trabalho da 4a Região e na Administração Pública ${ }^{1}$ em geral, e serão examinados no decorrer da presente seção.

1 Este artigo utiliza-se, aqui, do conceito subjetivo, formal ou orgânico de Administração Púbica. Seus termos exatos, ademais, podem ser conferidos em Di Pietro (2013, p. 50), que afirma: “(...) designa os entes que 
A Resolução no 151, de 2015, do CSJT, elenca em seus “considerandos", enquanto elementos de justificativa para a expedição do ato normativo, essencialmente: ${ }^{2}$ a) a competência do Conselho para expedir normas gerais de procedimento relacionadas à gestão de pessoas, no âmbito da Justiça do Trabalho; b) o princípio da eficiência, previsto ao art. 37, caput, da Constituição; c) razões de produtividade para os órgãos da Justiça do Trabalho, de primeiro e segundo grau, vinculando tal otimização de produtividade à melhoria da qualidade de vida dos seus servidores; d) a implantação do Processo Judicial Eletrônico na Justiça do Trabalho e e) o término da fase de experimento, prevista na Resolução no 109/2012.

Por sua vez, a Portaria no $5.791{ }^{3}$ de 2013 , do TRT da 4⿳亠丷 Região, indica, em sua motivação: a) novamente, o princípio da eficiência; b) a implantação do Processo Judicial Eletrônico na Justiça do Trabalho, que possibilita o trabalho remoto ou à distância; c) as vantagens e benefícios diretos e indiretos do teletrabalho para a Administração, para o servidor e para a sociedade e d) o disposto na Resolução no 109, de 2012, do CSJT (ora no 151/2015), que prevê a realização do teletrabalho nos órgãos da Justiça do Trabalho.

Têm-se, então, termos similares para a motivação dos instrumentos de regulamentação expedidos, no âmbito da Justiça do Trabalho, com destaque para o princípio da eficiência e a implantação do teletrabalho, a partir da instalação do processo eletrônico, inicialmente a título de experiência.

Dito isto, a Resolução no 151/2015 do CSJT indica, em suas disposições gerais, que será considerado teletrabalho o previsto no art. 2ํ:

Art. $2^{\circ}$ Para os fins de que trata esta Resolução define-se:

I - Teletrabalho: modalidade de trabalho realizado fora das dependências dos Órgãos da Justiça do Trabalho de primeiro e segundo graus, com a utilização de recursos tecnológicos.

Assim, fica estabelecido, para os fins administrativos no espectro exclusivo dos órgãos de primeiro e segundo graus da Justiça do Trabalho, que será teletrabalho aquele realizado fora de suas dependências, com a utilização de recursos de tecnologia.

exercem atividade administrativa; compreende pessoas jurídicas, órgãos e agentes públicos incumbidos de exercer uma das funções em que se triparte a atividade estatal: a função administrativa".

2 O instrumento regulamentar, ainda, faz referência ao Processo CSJT-AN-9223-30.2012.5.90.0000.

3 Texto compilado com as alterações promovidas pelas Portarias no $2.143 / 2014$ e nำ 5.488/2014. 
No particular, considerando-se o texto da Resolução antecedente, de no 109/2012, grande avanço se verifica com a supressão da proibição de mudança de domicílio ao servidor em teletrabalho. A princípio, era possível detectar que a regulamentação de Direito Administrativo para o teletrabalho diferia-se (e muito) da previsão do art. 6으 da CLT, pois diminuía o conceito de distância, impedindo que o servidor prestasse serviços fora de seu local de lotação. Ainda que se tenha por objetivo, nesse momento, apenas expor a regulamentação, guardando-se sua análise crítica para espaço seguinte, é importante indicar a distinção normativa então realizada na esfera administrativa.

O art. 6ำ da CLT é cristalino ao dizer que não sofrerá distinção o trabalho realizado na sede do empregador, em face daquele realizado no domicílio do empregado ou daquele realizado a distância, sendo relevante para a relação laboral a existência dos elementos que caracterizam a relação de emprego, apenas. Isso se dá em virtude de uma orientação maior (constitucional) e se lastreia no princípio da igualdade.

A Resolução no 109, de 2012, do CSJT, ao conceituar teletrabalho como aquele realizado fora do órgão de segundo ou primeiro graus da Justiça do Trabalho, impunha que seu exercício não acarretasse a mudança de domicílio do servidor, vedação que não é imposta na iniciativa privada, tampouco no serviço público presencial. Lado outro, em existindo a mudança de domicílio pelo servidor, designado por portaria para o teletrabalho, haveria quebra de requisito para a realização do teletrabalho, o que implicaria, para além da revogação do ato administrativo ordinatório, ${ }^{4}$ a possibilidade de imputação de responsabilidade administrativa ao agente público, ${ }^{5}$ entre outras consequências. O conceito positivado no art. $1^{\circ}$, da Resolução no 109, de 2012, do CSJT, divergia daquele albergado no art. 6ํㅡ, da CLT, equivocadamente oferecendo limite semântico a tudo o que se quis construir enquanto "trabalho a distância".

O parágrafo único do art. $2^{\circ}$ da Resolução atual mantém da resolução anterior a ideia de que o trabalho naturalmente exercido externamente à sede jurisdicional (mesmo que apenas em parte da jornada), como a atividade de Oficiais de Justiça, não pode ser objeto de teletrabalho. ${ }^{6}$

Sobre a classificação, ato administrativo ordinatório, a doutrina de Mazza (2011, p. 211), que relaciona: "são manifestações internas da Administração decorrentes do poder hierárquico disciplinando o funcionamento de órgãos e a conduta de agentes públicos".

5 A aparente "quebra de requisito" poderá ser classificada como violação a dever, prevista no art. 116, inciso III, da Lei Federal no 8.112, de 1990, que demanda a instauração de processo, firme o art. 143, a fim de apurar a irregularidade.

6 O parágrafo único do artigo $2^{2}$ da Resolução ํํ 151/2015 destaca: “Não se enquadram no conceito de teletrabalho as atividades que, em razão da natureza do cargo ou das atribuições da unidade de lotação, são desempenhadas externamente às dependências do Órgão". Entende-se que o texto, ora relacionado, 
Por fim, o art. 2ํㅡ, da Resolução nำ151/2015, do CSJT, determina e conceitua, com observância ao Poder Hierárquico, ínsito à estrutura administrativa, a existência de Gestor da Unidade, que poderá ser magistrado ou servidor ocupante de cargo em comissão e que responderá pelo gerenciamento; e de uma Chefia Imediata, que poderá ser criada na forma de cargo em comissão, ou função comissionada, ao qual se reportará o servidor em teletrabalho.

\subsection{Comentários aos capítulos I e II: Das disposições gerais e dos destinatários}

Relacionado à estrutura primária, donde advém o conceito de teletrabalho e a ideia de manutenção das relações da hierarquia, o art. 3ํ, da Resolução, por sua vez, ratifica que a realização do teletrabalho é facultativa, decorrendo de critério de conveniência e oportunidade (discricionariedade) do Tribunal. Ressalta que, somada à discricionariedade, a execução do teletrabalho é limitada às atribuições em que tal seja possível, conforme característica do serviço. Por fim, indica que a realização do teletrabalho só será possível se o órgão puder mensurar objetivamente o desempenho do servidor.

A regulamentação explanada indica que a decisão a favor daqueles servidores designados para o teletrabalho partirá do juízo de mérito do Tribunal $^{7}$, e da compatibilidade do cargo com as tarefas a serem realizadas, observado o critério da eficiência - já preconizado nos "considerandos" do ato regulamentador.

O critério de eficiência, ademais, surge como elemento fortificante da ideia de teletrabalho no Tribunal, restando positivado ao art. 4o, da Resolução, implícito nos termos "aumento da produtividade", "atrair, motivar e comprometer com os objetivos da instituição", "economia de custo e deslocamento", "sustentabilidade solidária”, "ampliação inclusiva” e "melhoria da qualidade de vida dos servidores”.

Especificamente, o art. 4을 inciso III, parece render-se ao princípio da sustentabilidade, argumento base deste inciso, ao referir:

Art. 4ㅇ 0 teletrabalho objetiva aumentar, em termos quantitativos e sem prejuízo da qualidade, a produtividade dos trabalhos realizados, e ainda:

preocupa-se, muito mais, em não permitir o desvio de função, que decorre da prática de ato administrativo que não se coaduna as atribuições (ou competência) do servidor público. Ou seja, trata-se de vedação ao desvio, espécie do gênero "abuso de competência”, ao invés de verdadeiro elemento de definição do teletrabalho na matéria administrativista.

7 Neste caso, é importante que se observe que a escolha discricionária do órgão administrativo não poderá violar o princípio da voluntariedade na implementação da modalidade laboral, o que permitiria práticas assediatórias. Neste sentido, a perspectiva de FINCATO $(2014$, p. 21). 


\begin{abstract}
[...]
III - contribuir para a melhoria de programas socioambientais dos Tribunais Regionais do Trabalho visando à sustentabilidade solidária do planeta, com a diminuição de poluentes na atmosfera e a redução no consumo de água, esgoto, energia elétrica, papel e de outros bens e serviços disponibilizados nos Órgãos da Justiça do Trabalho de $1^{\circ}$ ำ e $2^{\circ}$ graus; (grifou-se).
\end{abstract}

De fato, ao elencar a sustentabilidade como um dos objetivos do teletrabalho no Tribunal do Trabalho, o ato regulamentador empreende acerto, no que tange ao momento vivenciado pelo novo Direito Administrativo. Porém, no escopo deste estudo, é importante analisar o objetivo traçado ao inciso III, do art. 4ํㅡㄹ da Resolução em consonância aos demais princípios, bem como aos direitos fundamentais, dentre eles os direitos sociais.

Freitas (2012, p. 197), desde o primeiro momento, deixa claro acerca de sua posição perante o novo Direito Administrativo:

[...] em lugar de crer no Direito Administrativo do século XIX, baseado na suposta ( $e$, na realidade, seletiva) obediência às regras legais ou de ajoelhar perante os ícones da eficiência clientelista e imediatista (anos 1990), o novo paradigma abraça a eficiência intertemporal, numa postura compatível com a cidadania ativa e altiva, avessa à imposição unilateral e autoritária do sujeito sobre o objeto da regulação.

Assim, é importante verificar se, de fato, os critérios de eficiência parametrizados na Resolução no 151/2015 do CSJT coadunam-se àqueles pretendidos pelo novo Direito Administrativo. Ademais, ganha o mesmo grau de importância a adequação da normatização aos parâmetros da norma estatutária - Lei Federal no 8.112, de 1990 -, enquanto diploma que firma o Regime Jurídico Único dos Servidores Públicos Civis da União. ${ }^{8}$

A verificação, ora referida, implica a necessidade de coerência sistemática, especialmente entre os objetivos da Administração Pública e os comandos normativos da Resolução em estudo. De sobra, pode-se dizer ainda que a Resolução limita a compreensão do termo sustentabilidade ao foco ambiental, o que, como se aponta neste estudo, é uma grande simplificação.

8 Entende-se, inclusive, que ao referir no artigo 1ㅇ “... observada a legislação vigente”, a Resolução se refere ao Estatuto dos Servidores Públicos Federais, servindo de complemento a ela e, em nenhuma hipótese, podendo revogar, contrariar ou relativizar seus dispositivos. Recorde-se que a competência para legislar sobre matéria de serviço público federal é exclusiva do Poder Legislativo Federal (o que por si já geraria debate técnico-formal acerca da Resolução nำ151/2015 do CSJT). 
Desta forma, e prosseguindo com a análise, o art. 5ํ, do ato administrativo regulamentar relaciona os destinatários da norma, por óbvio, os servidores do órgão jurisdicional.

Assim, serão destinatórios da alternativa do teletrabalho aqueles servidores com deficiência (art. 5ํㅜ , inciso I), contemplando o objetivo de ampliar a possibilidade de trabalho aos servidores com dificuldade de deslocamento e possibilitando a estes melhor qualidade de vida (art. 4으, incisos IV e V).

A iniciativa do art. 5으, ao elencar destinatários e requisitos, ademais, promove certa confusão. Perceba-se que o inciso IV, do art. 5ํ, indica, de forma adequada, como destinatário do teletrabalho aquele servidor que tenha demonstrado comprometimento com as tarefas recebidas e habilidades de autogerenciamento do tempo e de organização, prestigiando o primado de eficiência à luz do art. 37, caput, da Constituição.

Porém, os incisos II, III e V, ${ }^{9}$ do mesmo art. 5으, parecem orientações ao gestor, não estando diretamente vinculados ao tema "destinatários" do teletrabalho, tarefa atendida pelos incisos I e IV, tão somente. Aliás, os incisos II, III e V poderiam ser remanejados, fazendo-os parágrafos, eis que de reconhecida importância para o funcionamento das unidades judiciárias.

Em tela, outras importantes diretrizes encontram-se dispostas no art. 5‥ A primeira destas diz respeito à adesão ao teletrabalho. Trata-se de verdadeira faculdade, conforme critério discricionário dos Tribunais Regionais do Trabalho, a ser adotada conforme os critérios de conveniência e oportunidade dos gestores, observada a necessidade do serviço, não sendo um direito ou um dever do servidor.

Ou seja, o principal critério para a adesão/concessão é a necessidade/conveniência do serviço. Assim, a demanda interna e externa do órgão é que irá propiciar a realização de teletrabalho pelos servidores. Esta demanda deverá estar motivada e relacionada como elemento a favor ou contra, conforme a exposição de motivos dos gestores de unidade.

Por sua vez, o art. 4ํㅗ $\S^{1}{ }^{\circ}$ da Resolução, firma que o teletrabalho não é direito ou dever do servidor. A questão deve ser absorvida da seguinte maneira: os

9 Seguem os incisos do art. 5ํ, da Resolução nำ 151, de 2015, do CSJT:

$(\ldots)$

II - o limite máximo de servidores em teletrabalho, por unidade, é de $30 \%$ da respectiva lotação, arredondando-se as frações para o primeiro número inteiro imediatamente superior, excluindo-se desse percentual os Assistentes de Juízes Titulares de Vara de Trabalho ou Substitutos e os gabinetes de Desembargadores; III - será mantida a capacidade plena de funcionamento dos setores em que haja atendimento ao público externo e interno;

(...)

$\mathrm{V}$ - promover, sempre que possível, o revezamento de servidores autorizados a realizar o teletrabalho, para que todos possam ter acesso a essa modalidade de trabalho. 
direitos dos servidores da Justiça do Trabalho, em que se incluem as vantagens remuneratórias, critérios para afastamentos, tempo de exercício e outros, estão previstos na Lei Federal no 8.112, de 1990, que dispõe sobre a norma aplicável aos servidores federais. Partindo-se da premissa de que possível uma leitura sistemática, então, o teletrabalho, como política laboral que promove verdadeira inovação no pacto entre tomador e prestador de serviço, não é direito a ser invocado a partir do Estatuto. Tampouco é direito adquirido do servidor, partindo de uma série de requisitos para a sua realização. É, tão só, uma modalidade de trabalho à disposição do gestor, que a utilizará nos limites da conveniência e necessidade do serviço, na forma e objetivo dos atos administrativos (com motivação, impessoalidade, etc.), sem observar a voluntariedade do servidor público, que deverá manifestar o desejo de assim prestar seus serviços.

O teletrabalho não poderá servir para "afastar" do órgão aqueles servidores de comportamento conflitante ou mesmo antissocial, sob pena de violação da natureza do instituto do teletrabalho, revelando-se o ato que assim impuser, ato eivado de abuso de autoridade. Em outra perspectiva, a Lei Federal no 8.112, de 1990, prevê penalidades a serem impostas ao servidor e que não poderão ser aplicadas na hipótese, por não se tratar o teletrabalho de um dever do servidor, uma vez que este não tem a obrigação de aceitar o teletrabalho, não podendo ser coagido a tal, permitindo-se-lhe, neste caso, impedir ou reverter a aplicação de penalidades disciplinares (art. 127) ${ }^{10}$ eventualmente destinadas a si, por negar-se a trabalhar fora da sede física da jurisdição em que lotado.

O procedimento previsto nos parágrafos do art. 5ำ, em síntese, referem ainda o encaminhamento pela chefia imediata da lista de servidores interessados ao gestor de unidade. Este, por sua vez, enviará a lista para o setor de pessoal, que poderá auxiliar na realização de futuro processo seletivo. 0 órgão de pessoal poderá indicar aqueles que possuam o perfil para teletrabalhar - o que convém ser feito dentro de critérios objetivos e de forma motivada, em que pese não estar escrito no dispositivo em análise, mas pressuposto por ser ato administrativo.

0 art. 6ำ da Resolução, por sua vez, lista os casos em que não é possível a realização de teletrabalho, organizando-os da seguinte forma:

\footnotetext{
10 Art. 127. São penalidades disciplinares:

I - advertência;

II - suspensão;

III - demissão;

IV - cassação de aposentadoria ou disponibilidade;

V - destituição de cargo em comissão;

$\mathrm{VI}$ - destituição de função comissionada.
} 
Art. 6 É vedada a realização de teletrabalho pelos servidores em estágio probatório; que tenham subordinados; e que tenham sofrido penalidade disciplinar (art. 127 da Lei no 8.112/90) nos dois anos anteriores à indicação.

Acerca do fato de que os servidores que se encontram no período do estágio probatório não poderão realizar o teletrabalho, primeiramente, tem-se que o instituto jurídico do estágio probatório resta em compasso ao da estabilidade, que, por sua vez, repousa no art. 41, caput, ${ }^{11}$ da Constituição. 0 art. 41 da Carta Magna de 1988, com as alterações impostas pela Emenda Constitucional oํ 19, em 1998, versa acerca do instituto jurídico da estabilidade, previsto ao servidor público de carreira, após o cumprimento do interstício temporal, indicado em seu texto.

Acerca do art. 41, o comentário de Di Pietro (2013, p. 986), na coletânea "Comentários à Constituição do Brasil", sobre a expressão "efetivo exercício", aduz:

Esse período compreendido entre o início do exercício e a aquisição da estabilidade é denominado de estágio probatório e tem por finalidade apurar se o servidor apresenta condições para o exercício do cargo, referentes à assiduidade, disciplina, eficiência e outros requisitos exigidos para o exercício do cargo. Desse modo, o servidor, depois de aprovado no concurso, nomeado e empossado no cargo, torna-se efetivo. Porém, só pode adquirir a estabilidade depois de cumpridos os três anos de efetivo exercício. Daí a afirmação corrente de que a efetividade é requisito para aquisição da estabilidade.

Desta feita, o art. 41, caput, prevê como "efetivo exercício" o critério de efetividade, para aquisição da estabilidade, que deverá ser verificado, conforme a legislação local. Em ditos coloquiais, a aferição da prestação da atividade regularmente vislumbrada, perante o cargo para o qual o servidor concursou.

Ou seja, de nada adianta a prestação da atividade em cargo estranho ao concurso público - como ocorre no caso das cedências para o exercício de função de confiança ou cargo em comissão no próprio ente, ou em outro órgão do Município ou das entidades políticas (União, Estados e Distrito Federal); da mesma forma, quando do exercício de mandato eletivo, onde não é possível a aplicação do art. 38, da Carta Republicana.

É interessante, ainda, a posição de Modesto (2002, p. 9-13), quando firma:

11 Art. 41. São estáveis após três anos de efetivo exercício os servidores nomeados para cargo de provimento efetivo em virtude de concurso público (Redação dada pela Emenda Constitucional no 19, de 1998). 
Assim, em resumo, não deve ser computado no estágio probatório:

a) licenças, afastamentos e outras hipóteses de ausência ao serviço referenciadas unicamente na situação peculiar dos agentes em estágio, quando houver funcionamento normal da administração pública;

b) períodos de tempo ficto, artificialmente construídos por lei ordinária;

c) o período de serviço prestado a outra pessoa ou entidade pública, para o mesmo ou outro cargo;

d) o período de serviço prestado à mesma pessoa ou entidade pública, relativamente a outro cargo público;

e) o período de serviço prestado à mesma pessoa ou entidade pública, relativamente ao mesmo cargo, porém como interino, substituto, prestador de serviços ou ocupante de função de confiança, antes da transformação da natureza do cargo;

Ou seja, existe, na doutrina, a intenção de que o servidor cumpra suas atividades no cargo para o qual concursou, afastando-se qualquer contagem de tempo ficto. Todavia, ainda que respeitada a posição doutrinária, não se vê adequação ao óbice ao art. 6o, no que diz respeito àqueles servidores em curso de estágio probatório não poderem realizar o teletrabalho.

Se a doutrina apresentada é cristalina ao afirmar que o período de estágio probatório será observado para apurar os requisitos de assiduidade, disciplina, eficiência, entre outros, que geram ao final a estabilidade; se estas mesmas posições, ainda, coíbem a contagem de tempo em afastamento - o que se considera acertado, pois aí estaria matéria estranha ao desempenho das atividades previstas em lei; se o teletrabalho não é hipótese de afastamento e, sim, desempenho de atividade que privilegia a qualidade de vida do servidor, sem desdenhar do cumprimento de metas e da aferição objetiva do trabalho prestado, vislumbra-se como critério de liberalidade do gestor (CSJT) a imposição do óbice, desde que apoiado na discricionariedade.

O desempenho de função de chefia, nos casos que admitem a sua criação (cuja raiz permanece no art. 37, V,12 da Constituição), indica, por sua natureza, a dedicação exclusiva do gestor público - ao menos é este o paradigma em vigor.

Se aceito, tal argumento permite o óbice previsto ao art. 6으 da Resolução, no que diz respeito à vedação da realização de teletrabalho pelos servidores que

12 Art. 37 (...) V - as funções de confiança, exercidas exclusivamente por servidores ocupantes de cargo efetivo, e os cargos em comissão, a serem preenchidos por servidores de carreira nos casos, condições e percentuais mínimos previstos em lei, destinam-se apenas às atribuições de direção, chefia e assessoramento; (Redação dada pela Emenda Constitucional no 19, de 1998). 
possuam subordinados. O Conselho, sendo assim, faz uso da sua governabilidade e indica a manutenção da dedicação exclusiva daqueles servidores que possuam as funções de direção e chefia.

Um exercício argumentativo permite questionar se a função de chefia não poderia ser exercida a distância, através do teletrabalho. Ou, de outra forma, que se averiguassem as razões que levariam o exercício desta a fracassar se realizada na forma teletrabalhada. Todavia, este mesmo exercício esbarraria, novamente, no conceito jurídico (indeterminado, mas não abstrato) da discricionariedade.

Por fim, no que pertine ao art. 6o e à vedação da realização de teletrabalho pelos servidores que tenham sofrido penalidade disciplinar (na forma do art. 127 do Estatuto Federal), nos dois anos anteriores à indicação, tem-no por critério relacionado à questão disciplinar.

Ocorre, neste caso, fenômeno similar aos eventos surgidos após o advento da Lei Complementar no 135, de 2010 (Lei da Ficha Limpa). Principalmente nos Municípios, foram editadas leis, com a mesma nomenclatura popular, onde se averiguam óbices a que indivíduos exonerados, no caso dos cargos públicos em comissão, ou demitidos, no caso de cargos públicos efetivos, fossem nomeados para novos cargos em comissão, haja vista passado com mácula disciplinar, o que implicava a chamada "Ficha Suja".

Entende-se por muita cautela, com relação a critérios similares de "Ficha Limpa”. Primeiramente, basta refletir que a Lei Complementar ํo 135, de 2010, foi alvo da ADI 4578, que discutiu a existência de diversos vícios de constitucionalidade. Não menos distante, as leis municipais que instituíram a "Ficha Limpa", em sua versão para as nomeações de cargos em comissão, também foram alvo de diversas ações de constitucionalidade, perante os Tribunais de Justiça Estadual. ${ }^{13}$

No presente caso, não se olvida que o óbice cumpre vetor de moralidade. Porém, tem-se que existe, neste, certo aspecto de nova penalidade, ou bis in idem, na medida em que inviabiliza a realização de teletrabalho, por quem houver sido punido, via estatuto. Aceito tal argumento, este poderia levar à inadequação do art. 6ํㅜ da Resolução.

13 De fato, existem diversos julgados. Citam-se, presentes no Tribunal de Justiça do Estado do Rio Grande do Sul: Ação Direta de Inconstitucionalidade no 70050430065, julgada em 27.01.2014; No Tribunal de Justiça de Santa Catarina o Al no 2013.088034-3, julgado em 10.06.2014; No Tribunal de Justiça do Estado do Paraná, Ação Direta de Inconstitucionalidade no 974.096-1, julgada em 16.12.2013. 


\title{
2.3 Comentários ao capítulo III: das condições para a realização do teletrabalho
}

Prosseguindo com a análise da norma, o Capítulo III, dos arts. $7^{\circ}$ ao 15, alinha o que denomina de "condições para a realização do teletrabalho", onde destacam-se as atividades passíveis de desempenho fora das dependências do tribunal (art. $7^{\circ}$ ).$^{14}$

No que concerne ao servidor, o Capítulo III indica diversos comandos a serem observados. Um dos mais importantes diz respeito à imposição de o servidor apresentar incremento na produtividade, a ser determinado e aferido pelo titular da unidade, nunca inferior a 15\% (art. 8ㅇ), o que foi mantido da Resolução antecedente.

O dispositivo é comentado por Fincato (2014, p. 21), ainda sob a égide da Resolução no 109/2012, que o posiciona em um rol de violações aos direitos fundamentais de caráter social:

\begin{abstract}
Ademais das questões basilares supra levantadas, a Resolução em seu conteúdo fere diversas matérias caras aos servidores públicos civis, conteúdos já pertencentes ao seu patrimônio jurídico subjetivo, formado especialmente por direitos fundamentais de caráter social (3a Dimensão dos Direitos Fundamentais). Em síntese e de forma meramente exemplificativa, seriam:

- quebra do princípio da igualdade entre servidores: estabelecimento de metas de desempenho $15 \%$ superiores às dos servidores com atuação presencial.
\end{abstract}

A indicação do cumprimento de metas aos servidores é ideia vinculada ao princípio da eficiência (art. 37, caput, da Constituição Federal). Por eficiência, dentro da sistemática de ressignificação do Direito Administrativo (FREITAS, 2012, p. 200), tem-se este como "vedação de meios inapropriados e o imperativo de alcançar o mais com o menos" (FREITAS, 2012, p. 203).

Ademais, o princípio da eficiência guarda relação com o princípio da eficácia, que implica a "vedação de descumprimento dos objetivos e metas constitucionais” (FREITAS, 2012, p. 203), sendo que ambos se conectam à meta de desenvolvimento durável.

14 A norma refere exemplos: confecção de minutas de sentenças, votos, pareceres, relatórios e propostas de atos normativos, dentre outros, etc. 
Para que se tenha a realização do desenvolvimento durável, indicado por Freitas (2012, p. 203), é necessário que a Administração estabeleça metas isonômicas de eficiência para os seus servidores.

Trosa (2001, p. 193), ao analisar a gestão pública por resultados, contribui para a discussão posta afirmando que para definir os resultados (ou metas a que se quer chegar) é necessário o cumprimento de etapas. Destaca, assim, que se deve analisar os atores ou partes envolvidas (stakeholder); por segundo, tem-se que observar a lógica da intervenção pretendida.

Como atores ou partes envolvidas no texto do art. 8o, da Resolução no 151/2015, aparecem o Tribunal do Trabalho (Administração Pública), os servidores que irão realizar o teletrabalho e, ao fundo, os servidores que operam nos órgãos da Justiça do Trabalho de forma presencial.

O que, de fato, não fica claro é a lógica da intervenção pretendida ao art. 8o. Se o dever de eficiência é imposto a todos, Tribunal e servidores, qual a razão dos servidores que realizam o teletrabalho terem que apresentar incremento na produtividade distinta dos colegas que operam presencialmente?

Se a eficiência objetivada deve estar adequada aos demais princípios de direito, sendo verdadeira prática sustentável, torna-se aparente certa violação ao princípio da igualdade, conforme asseverado por Fincato (2014, p. 21).

Ademais, parece haver maltrato à motivação do ato, no que concerne à lógica de intervenção da política adotada ao art. 8o, e não esclarecida no bojo da Resolução no 151/2015. Até porque se as atividades a serem realizadas pelos servidores no teletrabalho devem ser acordadas com a chefia (art. 9o) ${ }^{15}$ e, ainda, restar dentro daquelas previstas nas atribuições do cargo, não sofrendo distinção a conduta no que diz respeito, de servidor para servidor, dentro de um mesmo cargo. O único aspecto distinto é que o servidor, albergado pela Resolução no $151 / 2015$, realizará suas atividades na forma do teletrabalho.

Em um critério de paradigma de racionalidade imparcial (FREITAS, 2012, p. 206), norteada na forma intertemporal pelo princípio da eficiência (art. 37, caput, da CF) e seu correlato de eficácia (art. 74, da CF), a Administração deve expedir atos administrativos (sejam ordinatórios, normativos, ou enunciativos) qualificados pela ampla motivação, sob pena de violação à sustentabilidade.

No caso, não se vislumbra a racionalidade aventada, no art. 8o, e tampouco no art. 12, que impõe ao servidor a responsabilização por providenciar as estruturas tecnológicas necessárias à realização do teletrabalho. Neste ponto, pode-se

15 Art. 9 As atividades a serem realizadas por meio do teletrabalho devem ser previamente acordadas entre a chefia imediata e o servidor, mediante registros expressos no formulário de planejamento e acompanhamento de trabalhos, a ser adotado no âmbito de cada unidade, a partir de modelo proposto no Anexo desta Resolução. 
indagar se a mesma obrigação é imputada ao servidor que opera numa vara do trabalho.

Ainda, além do aspecto de violação ao critério de igualdade, parece haver conflito aparente entre o art. 12 e a primeira parte do texto do art. 16, pois ora a Resolução firma como obrigação do servidor providenciar as estruturas tecnológicas, ora afirma que o Tribunal irá disponibilizá-las.

Novamente, os dois aspectos suscitados poderão implicar que a política pretendida pelo Conselho Superior, ao regulamentar o teletrabalho, não se configure como prática sustentável (sequer viável). ${ }^{16}$

Prosseguindo, no que tange aos deveres dos servidores em teletrabalho, centralizados ao art. 13, tem-se pela sua conexão aos primados previstos ao art. 116 da Lei Federal no 8.112, de 1990, que dispõe sobre a norma estatutária.

Neste aspecto, não se vê óbice a que uma Resolução, espécie de ato administrativo normativo, acomode versão destes deveres aos servidores teletrabalhadores, desde que não implique incompatibilidade. Neste aspecto, afirma Zimmer (2009, p. 200):

Vale dizer que o centro de toda a atuação administrativa está nos impulsos gerados pelas leis e pelos atos normativos de caráter infralegal, por isso é dever do servidor público federal respeitar as leis e regulamentos (...)

Por sua vez, os arts. 14 e $16^{17}$ da Resolução no 151, de 2015, versam acerca do controle de frequência do servidor no sistema de teletrabalho. Acerca do controle de frequência, Fincato (2014, p. 21) afirma que na prática há "ausência de controle da jornada diária”, o que pode levar a excessos. Neste aspecto, tem-se que 0 art. 14 impõe, de forma acertada, a necessidade do registro.

16 Nesse aspecto, também o disposto no artigo 22 soa estranho ao impor aos Tribunais Regionais a orientação aos servidores em teletrabalho sobre aspectos de ergonomia e requisitos técnicos dos equipamentos a serem utilizados.

17 Art. 14. As unidades participantes do teletrabalho deverão registrar a frequência do período em que os servidores estiverem desenvolvendo suas atividades em regime de teletrabalho nos termos desta Resolução.

(...)

Art. 16. A unidade de tecnologia da informação do Tribunal viabilizará o acesso remoto aos servidores participantes da experiência do teletrabalho e disponibilizará as funcionalidades tecnológicas indispensáveis à realização das tarefas, assim como providenciará as adaptações necessárias no sistema de frequência de forma a viabilizar os lançamentos de que trata o art. 14 desta Resolução. 


\subsection{Comentários ao capítulo IV: Das disposições finais}

Por fim, enquanto dispositivo integrante da parte final da Resolução no 151/2015, o art. 16 afirma que o Tribunal deverá possibilitar o acesso remoto e as adaptações necessárias no sistema de frequência de forma a viabilizar os lançamentos do ponto.

A par das medidas, uma sugestão, dentro da perspectiva do Direito Administrativo sustentável, poderia passar pela dispensa do registro de ponto, com a aferição da efetividade através de outro ato. Tal ato, ademais, poderia ser a declaração de efetividade, assinada pela respectiva chefia do setor e homologada pelo gestor de unidade, tendo por base o cumprimento de metas.

A presente sugestão, em certos termos, promoveria o princípio da eficiência em potencial amplo, pois permitiria dar-Ihe um sentido econômico moderno, como, aliás, pretendeu a EC o 19, de 1998. Sobre o sentido aludido, as palavras de Gabardo (2002, p. 27):

Cumpre observar, ainda, que em um sentido econômico moderno, a racionalização tem como justificativa básica a melhoria do processo produtivo, sendo que o verbo "produzir" significa mais que simplesmente gerar ou realizar, pois implica a "criação de utilidades".

Gabardo (2002, p. 27), afirma, ainda:

A noção de produtividade adquiriu relevância, e até mesmo sucesso científico, mais recentemente, na medida em que, na prática decorreu da valorização do trabalho humano como atividade consciente encaminhada à geração de um bem econômico, característica da modernidade.

Deixa-se claro que o que se quer com a medida sugerida é prestigiar padrões de incremento na produção aplicados de forma igualitária, em paridade àqueles tidos para os servidores presenciais. Neste caso, a produtividade serviria para balizar não só a frequência do servidor, mas seu comprometimento com o programa; sua assiduidade e potencial.

Para Freitas (2012, p. 209) trata-se de dar combate, na forma da produção tempestiva e eficiente dos agentes públicos que adotem metas de prevenção e precaução, em lugar da gestão que chega tarde. O autor (FREITAS, 2012, p. 209) ainda afirma que:

[...] a transição da gestão pública que "chega tarde" para aquela que confere senso de urgência às medidas de prevenção e de precaução, 
de ordem a introjetar, mais do que nunca, uma mirada antecipatória nas relações administrativas. Para ilustrar, a fiscalização do trabalho deve coibir as condições ocupacionais cancerígenas.

Assim, tem-se que a produtividade tipificada em metas poderá ser a chave para uma nova posição ao controle de efetividade, decorrente de verdadeira valorização do trabalho laboral do servidor, afastado o simples conteúdo obrigacional de registro de ponto.

Nestes termos, existe experiência, interessante, promovida pela Secretaria da Receita Federal do Brasil, através da Portaria ํo 947, de 20 de abril de 2012. $\mathrm{O}$ art. 16, do ato normativo aludido, refere:

Art. 16. É responsabilidade dos gestores das áreas ou unidades participantes da experiência-piloto do Teletrabalho, subsidiados pelas chefias imediatas dos servidores em Teletrabalho:

I - manter registros específicos de dispensa formal de ponto dos servidores em regime de Teletrabalho, para o período de realização de trabalhos fora das dependências das unidades administrativas da RFB;

A iniciativa promovida pela Secretaria da Fazenda vai no sentido de manter registros (controle do ato) de dispensa formal (ou seja, depende de ato administrativo para complementar o comando normativo) de ponto dos servidores designados para o regime de teletrabalho, com a realização de atividades fora das dependências da unidade administrativa. ${ }^{18}$

O comando do art. 16, da Portaria no 947, de 2012, da Receita Federal é política inovadora na esfera pública e resta dentro da concepção de projeto-piloto, prevista em sua ementa e em seu texto, como se vê:

Art. 1ํFica instituída, a título de experiência-piloto, a realização de atividades, tarefas e atribuições fora das dependências físicas das unidades administrativas da Secretaria da Receita Federal do Brasil (RFB), na modalidade de Teletrabalho, pelos servidores integrantes da Carreira de Auditoria da RFB (ARFB), mediante a implantação do

18 Por importante, ressalte-se que o artigo 21 da Resolução estatui: “Em razão da natureza do teletrabalho, os servidores autorizados a exercer o trabalho remoto não terão direito à compensação de jornada, tampouco ao pagamento de horas extraordinárias", o que contribui para a ideia de superação da retribuição com base na disponibilidade (tempo), deslocando-a para a produtividade (metas). Cautela deve ser tomada, no entanto, no que tange à formalização disto, uma vez que o artigo 20 pode soar paradoxal ao garantir ao servidor em teletrabalho as mesmas normas aplicáveis às atividades desenvolvidas pelo servidor que atue nas dependências do Órgão Judiciário. 
Programa de Gestão de que trata o $6^{\circ}$ do art. 6을 do Decreto ํo 1.590, de 10 de agosto de 1995, nas atividades de análise e julgamento de processos administrativos fiscais e desenvolvimento de sistemas corporativos na área de tecnologia da informação.

$\S 1^{\circ}$ A realização do Teletrabalho ocorrerá a título de experiência-piloto, nas áreas ou unidades administrativas previamente autorizadas por ato específico do Secretário da RFB, devendo ser realizadas avaliações trimestrais de acompanhamento e avaliação das metas e dos resultados alcançados.

É claro, também aqui, o viés de uma proposta-piloto, com o fito de pleitear uma política sustentável de teletrabalho que se apresenta a partir dos termos da Resolução no 151, fortes os objetivos do seu art. 4‥ Assim, o modelo apresentado pela Secretaria da Fazenda do Brasil, ao regulamentar o teletrabalho na sua estrutura administrativa, é modelo sustentável, que poderá ser observado pela Justiça do Trabalho no aperfeiçoamento de sua experiência.

Por fim, é interessante indicar a presença da criação de Comissão, ao art. 19, da Resolução no 151/2015, cuja competência é assegurar a utilização adequada dessa modalidade de trabalho, tendo para isto as atribuições de: a) zelar pela observância da Resolução; b) acompanhar o desenvolvimento do teletrabalho no Tribunal; c) analisar e propor soluções aos problemas e omissões, entre outras atribuições inerentes à sua finalidade.

No que tange ao teletrabalho realizado no TRT da 4a Região, tem-se que a duração da experiência é determinada pela Portaria no 5.791, de 07 de agosto de 2013, com sua prorrogação pela Portaria no 4.690, de 14 de agosto de 2014.

Os arts. $1^{\circ}$ e $2^{\circ}$, desta última, sentenciam:

Art. 1을 Prorrogar, por mais 1 (um) ano, o prazo de que trata o art. 1응 da Portaria no 5.791/2013, que instituiu o teletrabalho no âmbito deste Tribunal, em caráter experimental.

Art. $2^{\circ}$ Esta Portaria entra em vigor na data de sua publicação.

Com a nova Resolução, do CSJT, entende-se que todos os Regionais estarão autorizados a atuar em regime de teletrabalho, nos termos em condições por esta impostos, bastando mero ato ratificatório.

\section{Conclusão}

Feitas as ponderações, tem-se o teletrabalho enquanto tema que se interliga ao atual movimento de sustentabilidade do Direito Administrativo. Trata-se de um 
nem tão novo modelo, na realidade hodierna, de relação de emprego, com prestação profissional da atividade, que privilegia a qualidade de vida do trabalhador, sem se esquecer do ideal de eficiência e de sustentabilidade.

Por ideal de eficiência, primou-se pela perspectiva aliada ao Direito Administrativo constitucional, que abdica de antigos paradigmas e propõe o interesse público a partir de juízo de ponderações; a vinculação da Administração à legalidade constitucional; a queda do espaço discricionário desmotivado e o advento da noção de Administração Pública com atos de regulamentação que deverão observar os direitos sociais e políticos, com seu controle pelo Poder Judiciário.

O passo adiante restou composto pela verificação do princípio da sustentabilidade, onde a Administração é responsável solidária pelo desenvolvimento material e imaterial da sociedade e de seus agentes públicos. Assim, o dever levado em consideração nesta pesquisa é de um Direito Administrativo sustentável, socialmente inclusivo, moderno, cujo objetivo máximo de sua eficiência é assegurar o bem-estar do indivíduo.

Desta forma, ao promover a análise da Resolução nํㅜ 151, de 2015, do Conselho Superior da Justiça do Trabalho, teve-se por objetivo averiguar se o instrumento normativo cumpre com as expectativas do Direito Administrativo constitucional e sustentável, observada a sua aplicabilidade ao parâmetro limite do Tribunal Regional da 4a ${ }^{a}$ Região - o que é reforçado pelas palavras detidas na Portaria no 5.791, de 07 de agosto de 2013, e sua sucessora, a Portaria no 4.690, de 14 de agosto de 2014, ambas oriundas do órgão administrativo desta competência.

Detectaram-se, então, algumas importantes considerações.

A fórmula de produtividade, eficiência e motivação, adotada pelo Conselho, no ato normativo, necessita de alguns ajustes. Neste caso, o art. 4ํ da Resolução no 151/2015 revela que o teletrabalho objetiva aumentar quantitativamente a produtividade dos trabalhos desempenhados, sem se esquecer da qualidade, primando - embora, neste aspecto, de forma restrita, porque nomina apenas questões ambientais - pelo princípio da sustentabilidade (inciso III, do dispositivo).

Ocorre que a coerência pretendida termina por colidir com o necessário trato de igualdade entre servidores de mesmo cargo. Assim é, pois, ao indicar as condições para a realização do teletrabalho, a Resolução termina por impor ao teletrabalhador incremento na produtividade nunca inferior a $15 \%$, ao passo que a mesma meta deveria ser exigida dos servidores em atendimento presencial no órgão da Justiça do Trabalho.

Se o princípio da sustentabilidade, dentro do plano de ressignificação do Direito Administrativo, pretende a eficiência enquanto vedação de meios inapropriados para alcançar o mais, a todo custo, a regra ao art. 8․․ merece revisão, pois, de fato, viola o primado do tratamento igualitário. 
Ademais, se o princípio em destaque é o da eficiência sustentável, uma proposta (na via do direito ao futuro) seria aquela encontrada no art. 16 da Portaria no 947, de 2012, da Receita Federal do Brasil. Neste caso, o órgão administrativo fazendário regulamentou o teletrabalho, em experiência-piloto, mantendo registros específicos de dispensa formal de ponto dos servidores designados para o regime, no que concerne ao período de realização de trabalhos fora das dependências das unidades.

Nessa senda, o cumprimento das suas metas de produtividade concederia parâmetro favorável à expedição de declaração da sua eficiência. Ou seja, para a política sustentável que se aventa, é necessário que o servidor esteja em dia com sua produção, o que o deixará em plena motivação e garantirá a eficiência pretendida.

Como já se falou, trata-se de uma proposta dentro do princípio da sustentabilidade, argumento que norteia este estudo, sendo útil repensar as vedações para a realização da nova modalidade laboral. As vedações, ora aludidas, estão presentes ao art. 6ํ, da Resolução, e levam em conta critério de escolha do Conselho, como no caso de não permitir a realização de teletrabalho por servidores que estão em estágio probatório.

Neste caso, aliás, a tentativa do argumento empregado foi no sentido de demonstrar que o período de estágio é aquele em que o servidor deve demonstrar requisitos de assiduidade, disciplina e eficiência, entre outros, e que tal não colide com a realização de teletrabalho pelo agente. Ou seja, trata-se de critério que carece de componente de motivação, fato contestado pelo Direito Administrativo Constitucional, pois escorado em curta discricionariedade.

Por sua vez, indicou-se argumento contrário à vedação de que os servidores com funções de confiança de chefia ou direção não poderão realizar o teletrabalho, lembrando que tal fato, novamente, retroage ao paradigma obsoleto do conceito jurídico indeterminado da conveniência e oportunidade.

Por fim, este texto coloca argumento contrário à vedação da realização de teletrabalho pelos servidores que tenham sofrido penalidade disciplinar nos dois anos anteriores à indicação, relacionando o tema à chamada "Ficha Limpa", na verdade o popular debate sobre a Lei da "Ficha Suja”. Aqui, advertiu-se para o fato de que o servidor poderá ser prejudicado por constar contra si uma penalidade até mesmo a mais branda, como a advertência - o que implicará novo tratamento desigual, no que pertine à realização do teletrabalho pelos agentes públicos.

Diante do exposto, esta pesquisa não possui qualquer pretensão de exaurir o tema, mas, sim, de lançar-se à análise da Resolução № 151/2015, do Conselho Superior da Justiça do Trabalho, perante o princípio da sustentabilidade e frente ao Direito Administrativo Constitucional; bem como relacionar termos para um 
diálogo, diante do fato do implemento do termo da experiência com o teletrabalho referido na Portaria no 4.690, de 14 de agosto de 2014, no Tribunal Regional do Trabalho da 4⿳亠 Região.

Uma nova portaria do Tribunal, certamente, deverá consolidar a realização do teletrabalho na Justiça do Trabalho da 4a Região. Todavia, o momento não deixa de ser importante, sugerindo-se sejam observadas as anotações, ora referidas, que poderão ser úteis para garantir a boa aplicação da nova tecnologia desenvolvida, a partir do instituto jurídico do teletrabalho devida e casuisticamente regulamentado e, principalmente, partindo-se de uma visão de Direito Administrativo sustentável.

\title{
The teleworking in the region fourth labor justice and the principle of sustainability
}

\begin{abstract}
This study aims to carry out the analysis of Resolution 151, 2015, the Superior Council of Justice of Labor (CSJT) as well as in the background of the Ordinance in 5791, to August 7, 2013, issued by the Regional Court work of the $4^{\text {th }}$ Region, and promoting teleworking before the Labor Court of the $4^{\text {th }}$ Region. The reading for this effort will be made taking legal basis for the principle of sustainability, which reflects duty to new position of Public Administration, before the administrative law.
\end{abstract}

Keywords: Telework. Sustainability. Labour Court of the $4^{\text {th }}$ Region. Resolution 109 of 2012. Higher Council of the Labour Court.

Contents: Introduction - $\mathbf{1}$ Telecommuting: concept and context to the (new) Administrative Law - 2 The regulation of telework in the Labor Court of the $4^{\text {th }}$ Region: Sustainability - Conclusion - References

\section{Referências}

BINENBOJM, Gustavo. Uma Teoria do Direito Administrativo: Direitos Fundamentais, Democracia e Constitucionalização. 2. ed. Rio de Janeiro: Renovar, 2008.

BRASIL. Conselho Superior da Justiça do Trabalho. RESOLUÇÃO № 109, DE 29 DE JUNHO DE 2012. Disponivel em: <www.tst.jus.br>. Acesso em: 05 abr. 2015.

BRASIL. Conselho Superior da Justiça do Trabalho. RESOLUÇÃO № 151, DE 29 DE MAIO DE 2015. Disponível em: <www.tst.jus.br>. Acesso em: 07 jun. 2015

BRASIL. TRIBUNAL REGIONAL DO TRABALHO DA 4ㄹ REGIÃO. PORTARIA № 5.791, DE 07 DE AGOSTO DE 2013. Disponivel em: <www.trt4.jus.br/Portarias>. Acesso em: 28 mar. 2015.

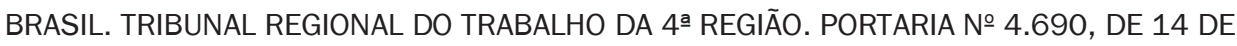
AGOSTO DE 2014. Disponível em: <www.trt4.jus.br/Portarias>. Acesso em: 28 mar. 2015.

BRASIL, SECRETARIA DA FAZENDA. PORTARIA № 947, DE 20 DE ABRIL DE 2012. Disponível em: <http://sijut2.receita.fazenda.gov.br/>. Acesso em: 25 maio 2015.

DI PIETRO, Maria Sylvia Zanella. Comentário ao art. 41. In: CANOTILHO, J. J. Gomes; MENDES, Gilmar F.; SARLET, Ingo W.; STRECK, Lenio L. (Coords.). Comentários à Constituição do Brasil. São Paulo: Saraiva/Almedina, 2013. p. 986. 
DI PIETRO, Maria Sylvia Zanella. Direito administrativo. 26. ed. São Paulo: Atlas, 2013.

FINCATO, Denise. Teletrabalho na Administração Pública brasileira. Case: “Regulamentação" pelo CSJT. Panorama Legal, v. 5, n. 1, p. 19-25, jun. 2004.

FREITAS, Juarez. $O$ controle dos atos administrativos e os princípios fundamentais. 4. ed. São Paulo: Malheiros Editores, 2009.

FREITAS, Juarez. Sustentabilidade: direito ao futuro. 2. ed. Belo Horizonte: Fórum, 2012.

GABARDO, Emerson. Princípio constitucional da eficiência administrativa. São Paulo: Dialética, 2002.

MAZZA, Alexandre. Manual de direito administrativo. 1. ed. São Paulo: Saraiva, 2011.

MODESTO, Marco Paulo. Estágio Probatório: Questões controversas. In: Revista Diálogo Jurídico, Bahia, n. 2, p. 1-28, mar. 2002. Disponível em: <http://www.direitopublico.com. $\mathrm{br} /$ pdf_12/DIALOGO-JURIDICO-12-MARCO-2002-PAULO-MODESTO.pdf>. Acesso em: 15 maio 2015.

ROCHA, Cláudio Jannotti da; MUNIZ, Mirella Karen de Carvalho Bifano. O teletrabalho à luz do artigo 6을 da CLT: O acompanhamento do direito do trabalho às mudanças do mundo pós-moderno. In: Rev. Trib. Reg. Trab. ${ }^{a}{ }^{2}$ Reg., Belo Horizonte, v. 57, n. 87/88, p. 101-115, jan./dez. 2013.

TEIXEIRA, Sergio Torres. O novo modelo de relação de emprego - repercussões das inovações tecnológicas sobre os elementos estruturais do vínculo empregatício. In: Revista $L T R, \mathrm{n} .10$, v. 60, p. 1310, out. 1996.

TROSA, Sylvie. Gestão pública por resultados: Quando o Estado se compromete. Rio de Janeiro: Revan, 2001.

ZIMMER JÚNIOR, Aloísio. Servidor Público Federal: Lei 8.112/1990 - Comentada artigo por artigo. Rio de Janeiro: Forense, 2009.

Recebido em: 01.12.2015

Pareceres: 13.06.2016 e 07.07.2016

Aprovado em: 12.07.2016

Informação bibliográfica deste texto, conforme a NBR 6023:2002 da Associação Brasileira de Normas Técnicas (ABNT):

FINCATO, Denise Pires; CHRISTOFOLI, Daniel Pires. O teletrabalho na Justiça do Trabalho da 4a Região e o princípio da sustentabilidade. Direitos Fundamentais \& Justiça, Belo Horizonte, ano 10, n. 34, p. 269-294, jan./jun. 2016. 